JOURNAL OF MECHANICAL ENGINEERING, MANUFACTURES, MATERIALS AND ENERGY

Available online http://ojs.uma.ac.id/index.php/jmemme

\title{
Unjuk Kerja Sistem Pembangkit Listrik Menggunakan Biogas Limbah Cair Pada Pabrik Kelapa Sawit
}

\section{Performance of the Power Plant System Using Biogas Liquid Waste at the Palm Oil Mill}

\author{
Husin Ibrahim ${ }^{1}$ *, Darianto2), Dicky Dwi Cahya ${ }^{2)}$ \\ 1) Teknik Mesin, Politeknik Negeri Medan, Indonesia \\ 2) Teknik Mesin, Universitas Medan Area, Indonesia \\ *husinibrahim@yahoo.co.id
}

\begin{abstract}
Abstrak
Pada umumnya, peralatan PLTBS di PT. Ukindo telah dirancang dengan menggunakan peralatan khusus untuk memproduksi listrik, seperti: engine gas dan generator. Perusahaan ini merupakan salah satu pabrik kelapa sawit (PKS) yang dapat menghasilkan energi listrik melalui teknologi energi terbarukan. Bahan bakar yang digunakan ialah limbah cair hasil pengolahan PKS (POME). Tujuan penelitian ini ialah analisa potensi energi listrik yang dapat dibangkitkan oleh PLTBS dengan menggunakan bahan bakar POME pada proses pengolahan TBS di pabrik kelapa sawit PT. Upkindo. Limbah yang keluar dari pipa masuk ke bak penampungan limbah di tiup oleh cooling tower. Setelah suhu limbah mendingin, limbah akan dipompa oleh Raw effluet feed masuk ke Digester Tank dan selanjutnya menghasilkan gas metana. Hasilnya ialah pada rata-rata pengolahan diatas ton $300 \mathrm{TBS} /$ tahun, hasil analisis perhitungan diperoleh daya listrik yang dapat dibangkitkan ialah 1,3 MW. Jika kemudian jumlah TBS diolah lebih besar, maka potensi daya yang dihasilkan jika akan lebih besar, sehingga daya terpasang juga dapat meningkat. Kata Kunci: Limbah Cair, Biogas, Pembangkit Listrik
\end{abstract}

\begin{abstract}
In general, PLTBS equipment at PT. Ukindo has been designed using special equipment to produce electricity, such as: gas engines and generators. This company is one of the palm oil mills (PKS) that can produce electricity through renewable energy technology. The fuel used is liquid waste from processing of PKS (POME). The purpose of this study is to analyze the potential of electrical energy that can be generated by the PLTBS using POME fuel in the processing of TBS in the palm oil mill of PT. Ukindo. The waste that comes out of the pipe enters the waste storage tank is blown by the cooling tower. After the waste temperature cools, the waste will be pumped by raw effluet feed into the Tank Digester and then produce methane gas. The result is that on average processing above tons of $300 \mathrm{TBS} /$ year, the results of the analysis of calculations obtained by the electric power that can be generated is $1.3 \mathrm{MW}$. If then the amount of TBS processed is greater, then the potential power produced if it will be greater, so that the installed power can also increase.
\end{abstract}

Keywords: Liquid Waste, Biogas, Power Plant

How to Cite: Ibrahim, H, 2018. Unjuk Kerja Sistem Pembangkit Listrik Menggunakan Biogas Limbah Cair Pada Pabrik Kelapa Sawit, JMEMME, 2 (2): 78-85 


\section{Husin Ibrahim, Unjuk Kerja Sistem Pembangkit Listrik Menggunakan Biogas Limbah Cair Pada Pabrik Kelapa Sawit}

\section{PENDAHULUAN}

Permintaan

mengurangi pencemaran udara, tanah, air, meningkat setiap tahunnya menjadi masalah cair.

tersendiri disetiap negara di dunia Pabrik akan melakukan kegiatan (Ensikom, S., 2016). Begitu pula dengan produksi biogas yang akan menghasilkan Indonesia, khususnya Sumatera Utara. gas metana dari limbah kelapa sawit. Pertumbuhan beban yang tidak diikuti Proses ini terdiri dari beberapa tahapan. dengan pertambahan pusat pembangkit Tahapan utama ialah tahapan keempat tenaga listrik menyebabkan krisis energi yaitu proses prombakan asam asetat, listrik. Di sisi lain bertambahnya kebutuhan karbon dioksida, dan juga gas hidrogen manusia menyebabkan pertumbuhan menggunakan bakteri metan, sehingga industri juga meningkat yang diiringi dihasilkan gas metana dan karbon dengan meningkatnya permasalahan dioksida.

tentang lingkungan.

Biogas terbentuk secara alami ketika

Salah satu industri yang cukup penting limbah cair kelapa sawit (POME) teruarai dalam memenuhi kebutuhan umat manusia pada kondisi anaerob. Tanpa pengendalian, adalah industri pengolahan kelapa sawit. biogas merupakan kontributor utama bagi Industri pengolahan kelapa sawit tersebut perubahan iklim global. Jika pengelolaan menghasilkan limbah yang berpotensi POME tidak terkendali, metana di dalam mencemari lingkungan. Secara garis besar biogas terlepas langsung ke atmosfer. limbah dalam industri pengolahan kelapa Sebagai gas rumah kaca (GRK), metana sawit dapat dibagi dua yaitu limbah cair dan mempunyai efek 21 kali lebih besar limbah padat. Limbah padat terdiri dari tiga dibandingkan dengan hidrokarbon. jenis yaitu tandan kosong, cangkang dan Pembangkit listrik tenaga biogas serabut. Pada umumnya, pabrik pengolahan mengambil manfaat dari proses kelapa sawit menggunakan limbah padat penguraian alami untuk membangkitkan serabut sebagai bahan bakar boiler pabrik listrik. Limbah cair organik yang dihasilkan itu sendiri, sehingga yang menjadi masalah selama produksi kelapa sawit merupakan adalah cangkang sawit dan tandan kosong sumber energi besar yang belum banyak sawitnya. Oleh karena itu, diperlukan solusi dimanfaatkan di Indonesia. Mengubah untuk mengatasi masalah-masalah yang POME menjadi biogas untuk dibakar dapat berkaitan dengan defisit pasokan tenaga menghasilkan energi sekaligus mengurangi listrik serta pengolahan limbah PKS tersebut dampak perubahan iklim dari proses sehingga kebutuhan umat manusia produksi minyak kelapa sawit. terpenuhi tetapi tetap tidak mencemari Pemanfaatan limbah padat dan cair lingkungan.

Biogas merupakan gas yang dihasilkan dari limbah cair pabrik kelapa sawit (POME) oleh mikroorganisme dalam kondisi anaerobic (Panji, 2013). Beberapa keuntungan dari pemanfaatan biogas adalah mengurangi efek gas rumah kaca, dapat dikonversikan menjadi energi listrik (Deublein, dan Steinhauster, 2008). Komponen terbesar yang terkandung dalam biogas adalah $\mathrm{CH}_{4}(55 \%-70 \%)$ dan $\mathrm{CO}_{2}(30 \%-45 \%)$ serta sejumlah kecil, nitrogen dan hidrogen sulfida. Apabila 
kandungan gas metan dalam biogas lebih dari 50\%, biogas tersebut layak digunakan sebagai bahan bakar, bersifat mudah meledak dan terbakar. Gas metana memiliki nilai kalor 50,1 MJ/kg. Jika densitas methana $0,717 \mathrm{~kg} / \mathrm{m}^{3}$, gas $1 \mathrm{~m}^{3}$ methana akan memiliki energi setara dengan 35,9 MJ atau sekitar $10 \mathrm{kWh}$. Jika kandungan gas methana adalah $62 \%$ dalam biogas, biogas $1 \mathrm{~m}^{3}$ akan memiliki tingkat energi sebesar 6,2 kWh, dengan asumsi efisiensi konversi biogas menjadi sifat dan kualitas biogas sebagai bahan bakar, seperti di tunjukan tabel 1.

Tabel 1. Komposisi Biogas.

\begin{tabular}{lll}
\hline No & $\begin{array}{l}\text { Komposisi } \\
\text { Biogas }\end{array}$ & Jumlah \\
\hline 1 & Methana () & $55-70 \%$ \\
2 & Karbon Dioksida & $30-45 \%$ \\
& O & \\
3 & Nitrogen 0 & $0-0,3 \%$ \\
4 & Hidrogen & $1-5 \%$ \\
\multicolumn{3}{l}{ Sulfida (S) } \\
\hline \multicolumn{3}{l}{ Sumber: Deublein dan Steinhauster, 2008) }
\end{tabular}

Kandungan $\mathrm{CO}_{2}$ dalam biogas sebesar 25 - $50 \%$ dapat mengurangi nilai kalor bakar dari biogas tersebut (Iqbal, 2008). Sedangkan, kandungan $\mathrm{H}_{2} \mathrm{~S}$ dalam biogas dapat menyebabkan korosi pada peralatan dan perpipaan dan nitrogen dalam biogas juga dapat mengurangi nilai kalor bakar biogas tersebut. Pada lower explosion limit (LEL) 5,4 vol \% metana dan upper explosion limit (UEL) 13,9 vol \%. Di bawah 5,4\% tidak cukup metana sedangkan di atas $14 \%$ terlalu sedikit oksigen untuk menyebabkan ledakan. Temperatur yang dapat menyebabkan ledakan sekitar 650$750{ }^{\circ} \mathrm{C}$, yaitu berupa percikan api atau korek api sudah cukup panas untuk menyebabkan ledakan.

Indonesia saat ini merupakan produsen minyak kelapa sawit terbesar di dunia , tercatat pada tahun 2011 terdapat sekitar 608 pabrik pengolahan kelapa sawit (Ditjen dan pemanfaatan energi, 2001). Bagian utama dari suatu fasilitas komersial konversi POME menjadi biogas ditunjukan pada Setiap komponen dalam gambar 1.

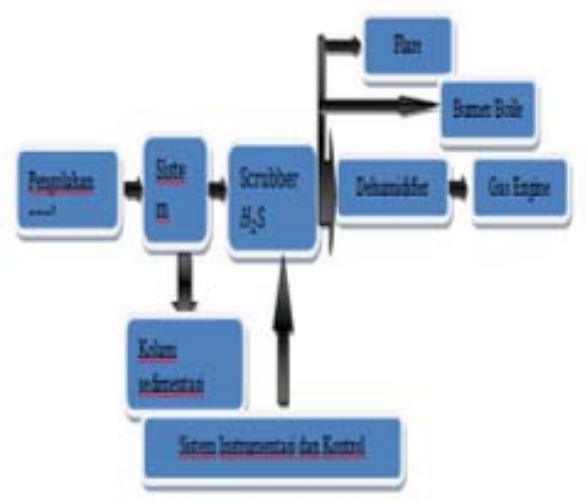

Gambar 1 Diagram Pembangkit Listrik Tenaga Biogas.

Sumber : Winrock Internasional 2015

Pengertian pembakaran secara umum yaitu terjadinya oksidasi cepat dari bahan bakar disertai dengan produksi panas dan cahaya. Pembakaran sempurna bahan bakar terjadi jika ada pasokan oksigen yang cukup. Dalam setiap bahan bakar, unsur yang mudah terbakar adalah karbon, hidrogen, dan sulfur. Tujuan dari pembakaran yang sempurna adalah melepaskan seluruh panas yang terdapat dalam bahan bakar. Hal ini dilakukan dengan pengontrolan "Tiga $\mathrm{T}$ " (Mitzlaff, 2000), yaitu : 


\section{Husin Ibrahim, Unjuk Kerja Sistem Pembangkit Listrik Menggunakan Biogas Limbah Cair Pada Pabrik Kelapa Sawit}

\section{T-Temperatur}

Temperatur yang digunakan dalam pembakaran yang baik harus cukup tinggi sehingga dapat menyebabkan terjadinya reaksi kimia.

\section{T-Turbulensi}

Turbulensi pada dasarnya menyebabkan efek dan terjadinya pencampuran yang baik antara bahan bakar dan bahan oksidasi.

\section{T-Time (Waktu)}

Waktu yang cukup agar input panas dapat terserap oleh reaktan sehingga berlangsung proses termokimia.

Dalam proses pembakaran tidak terlepas dari tahap awal yaitu penyalaan dimana keadaan transisi dan tidak reaktif menjadi reaktif karena dorongan eksternal yang memicu reaksi termokimia diikuti dengan transisi yang cepat sehingga pembakaran dapat berlangsung. Penyalaan terjadi bila panas yang dihasilkan oleh pembakaran lebih besar dari panas yang hilang ke lingkungan. Dalam proses penyalaan ini dapat dipicu oleh energi thermal yang merupakan transfer energi thermal ke reaktan oleh konduksi, konveksi, radiasi atau kombinasi dari ketiga macam proses tersebut.

Pembakaran yang sempurna akan menghasilkan tingkat konsumsi bahan bakar ekonomis dan berkurangnya besar kepekatan asap hitam gas buang karena pada pembakaran sempurna campuran bahan bakar dan udara dapat terbakar seluruhnya dalam waktu dan kondisi yang tepat. Kualitas bahan bakar perlu diperhatikan sesuai dengan karakteristiknya sehingga homogenitas campuran bahan bakar dengan udara terjadi secara sempurna. Sistem biodigester terdiri dari proses pengolahan awal, bio-digester, dan kolam sedimentasi.

Dalam proses pengolahan awal, POME dikondisikan untuk mencapai nilainilai parameter yang dibutuhkan untuk masuk ke digester. Pada tahap ini, dilakukan proses penyaringan untuk menghilangkan partikel besar seperti kotoran atau serat. Proses pengadukan dan netralisasi $\mathrm{pH}$ dilakukan untuk mencapai pH optimal pada 6,5-7,5. Sebuah sistem pendingin (coooing tower atau heat exchanger) berfungsi untuk menurunkan suhu POME menjadi sekitar $40^{\circ}-50^{\circ} \mathrm{C}$. Suhu digester harus di jaga dibawah $40^{\circ} \mathrm{C}$ agar kondisi mesofilik optimal. Penurunan suhu ini juga dibantu dengan proses resirkulasi air limbah keluaran dari digester. Air limbah setelah pengolahan awal dipompa ke bio-digester dalam bentuk kolam tertutup atau CSTR. Proses penguraian POME menghasilkan biogas dan residu (slurry). Digesterharus dirancang kedap udara dan air. Digester dapat dibuat dalam berbagai bentuk dan ukuran, dan dari berbagai bahan. Ukuran digester ditentukan berdasarkan laju aliran POME, beban COD, dan waktu retensi hidrolik (HRT) yang diperlukan untuk penguraian yang optimal (Herringshaw, 2009).

Air limbah hasil proses anaerobik dari digester mengalir ke kolam sedimentasi dimana POME yang telah terurai dipisahkan lebih lanjut dari lumpur dan padatan. Perkebunan dapat menggunakan limbah cair dari sedimentasi sebagai pupuk. Sistem pembuangan padatan berfungsi untuk memisahkan lumpur dan padatan yang terakumulasi baik di dalam digester maupun di dalam kolam sedimentasi. Biogas yang dihasilkan 
melalui proses anaerobik terkumpul di bawah cover (penutup) digester pada kolam tertutup atau pada bagian atap tangki pada sistem tangki/CSTR. Sistem kolam tertutup mempertahankan tekanan rendah 0-2 mbarg (tergantung pada desain penyedia teknologi), sementara sistem tangki menyimpan biogas pada tekanan yang lebih tinggi yakni 8-30 mbarg. Pabrik pengolahan kelapa sawit umumnya tidak menggunakan tangki penyimpanan biogas yang terpisah karena biayanya tinggi. Sistem tangki memiliki kapasitas penyimpanan biogas antara 30 menit hingga 3 jam, sedangkan kolam tertutup memiliki kapasitas penyimpanan 1 hingga 2 hari. Biogas yang terkumpul di dalam digester kemudian dialirkan dan diproses lebih lanjut ke dalam sistem pengolahan gas atau dibakar di dalam flare. Bentuk tangki CSTR dan kolam tertutup diperlihatkan pada gambar 2 .

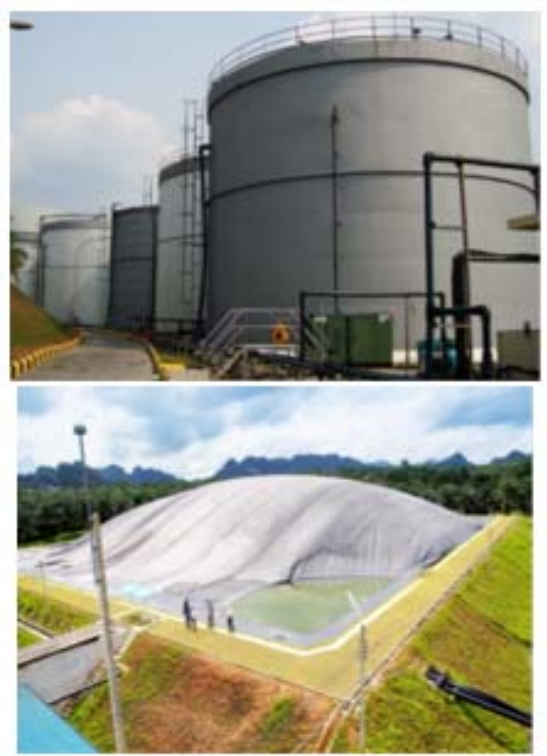

Gambar 2. Continously Stirred Tank Reactor(kiri) dan Kolam tertutup(kanan). Sumber : Winrock Internasional 2015.
Gas engine termasuk mesin pembakaran dalam yang bekerja dengan bahan bakar gas seperti gas alam atau biogas. Setelah kandungan pengotor pada biogas diturunkan hingga kadar tertentu, biogas kemudian dialirkan ke gas engine untuk menghasilkan listrik. Bergantung pada spesifikasi gas engine yang digunakan, gas engine yang berbahan bakar biogas umumnya memerlukan biogas dengan kadar air di bawah $80 \%$ dan konsentrasi S kurang dari 200 ppm.

Gas engine mengubah energi yang terkandung dalam biogas menjadi energi mekanik untuk menggerakkan generator yang menghasilkan listrik. Biasanya gas engine memiliki efesiensi antara 36-42\%. Bentuk gas engine diperlihatkan pada gambar 3.

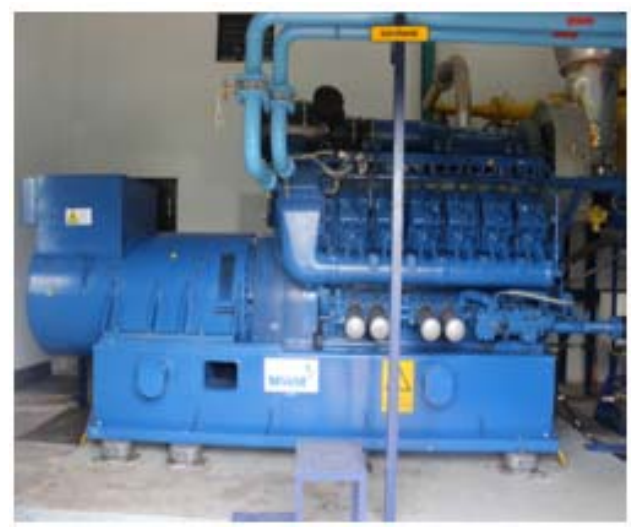

Gambar 3 Gas Engine. Winrock Internasional 2015

Sumber : Winrock Internasional 2015.

Biogas yang dihasilkan dari proses penguraian anaerobik dapat menjadi bahan bakar boiler. Burner gas biasanya dipasang pada dinding boiler. Biogas merupakan bahan bakar alternatif bagi boiler untuk menghasilkan panas atau listrik menggantikan bahan bakar biomassa, seperti cangkang dan serat, yang 
biasa digunakan di pabrik kelapa sawit. Bentuk burner diperlihatkan pada gambar 4.

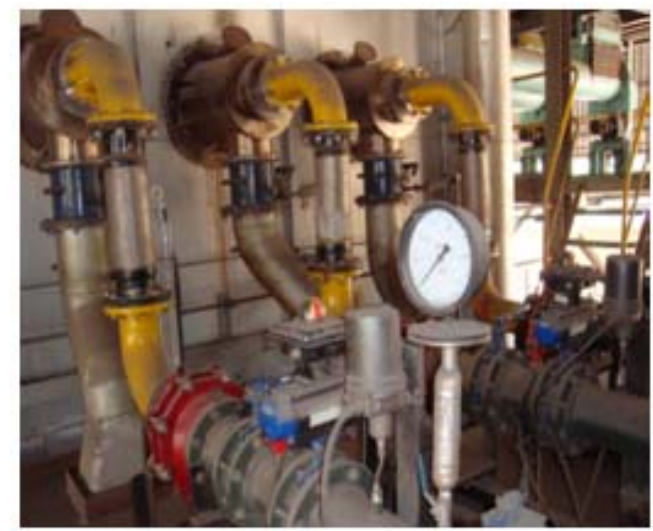

Gambar 4 Burner Biogas.

Sumber : Winrock Internasional 2015.

Flare digunakan di industri proses atau pabrik untuk membakar kelebihan gas. Dengan alasan keamanan, pembangkit listrik dengan biogas harus memasang flare untuk membakar kelebihan gas, terutama pada saat biogas tidak bisa diumpankan ke gas engine atau peralatan pembakaran lainnya. Umumnya hal ini terjadi saat puncak panen tandan buah segar, yang menyebabkan kelebihan produksi biogas. Bentuk unit flare diperlihatkan pada gambar 5.

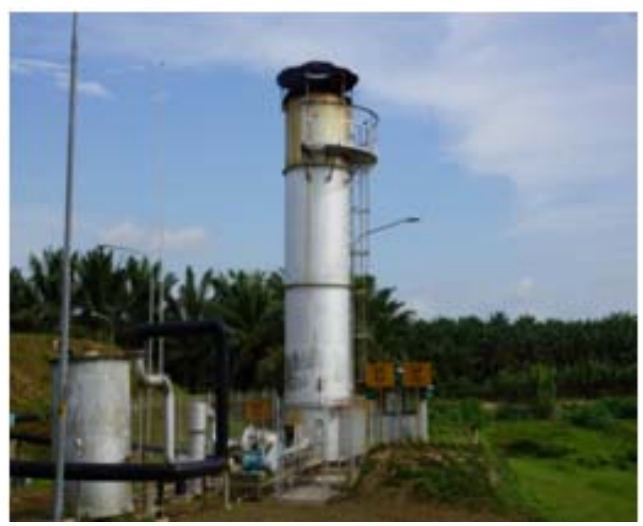

Gambar 5 Flare Biogas.

Sumber : Winrock Internasional 2015.
Operator tidak boleh melepaskan kelebihan biogas secara langsung ke atmosfer karena sifatnya yang mudah terbakar pada konsentrasi tinggi. Selain itu, pelepasan biogas secara langsung juga berarti pelepasan gas rumah kaca ke atmosfer seperti layaknya di penggunaan kolam limbah terbuka

Tujuan penelitian ini ialah analisa potensi energi listrik yang dapat dibangkitkan oleh PLTBS dengan menggunakan bahan bakar POME pada proses pengolahan TBS di pabrik kelapa sawit PT. Upkindo.

\section{METODE PENELITIAN}

Bahan yang dipergunakan dalam penelitian ini ialah POME (limbah cair kelapa sawit). Alat yang dipergunakan terdiri dari cooling tower, kolam penampung POME (limbah cair kelapa sawit), Raw effluent feed tank (tangki penampungan limbah mentah), Digester tank (gas metana), covered lagoon compart ment 1, covered lagoon compartment 2, covered lagoon compartment 3, solid removal tank (tangki zat padat limbah), scrubber (tangki gas clean/gas bersih s), PTU (ruangan untuk mengendalikan gas bersih masuk ke mesin chiller/pendingin, mesin chiller, dan flare (flaring).

Limbah yang keluar dari pipa masuk ke bak penampungan limbah di tiup oleh cooling tower agar udara panas pada limbah berkurang. Setelah suhu limbah mendingin, limbah akan dipompa oleh Raw effluet feed masuk ke Digester Tank. Limbah yang masuk ke Digester Tank akan menguap dan menghasilkan gas metana. Apabila gas metana berlebih akan di alirkan ke covered lagoon compartment 1, 2 dan 3. Lalu gas clean (bersih) akan 
ditampung di tangki scubber, dengan temperatur gas $40-50^{\circ} \mathrm{C}$. Gas tersebut didinginkan oleh mesin chiller sebelum disupplay ke gas engine. Kebutuhan gas untuk pabrik berbeda-beda setiap harinya. Jika ada gas yang berlebih, gas tersebut akan dibakar oleh alatflaring (flare). Gas akan di alirkan ke engine gas di saat engine gas membutuhkan bahan bahan bakar gas melalui tekanan mixer gas.

\section{HASIL DAN PEMBAHASAN}

Dengan analisis neraca massa didapatkan rata-rata POME sebesar 55\% dari total TBS terolah pada PT.UKINDO, maka total produksi POME dihitung sebagai berikut:

$\begin{array}{ll}\text { Kapasita olahan }= & 30 \mathrm{ton} / \mathrm{jam} \\ \mathrm{POME} / \text { AIR } & 1000 \mathrm{~kg} / \mathrm{jam} \\ \mathrm{COD} \text { POME } & 62.000 \mathrm{mg} / \mathrm{l}=0,062 \\ & \mathrm{~kg} / \mathrm{l}=0,35 \% \\ = & 8900 \mathrm{kkal} / \text { Watt } \\ \text { Nilai kalor } & 35 \% \\ \text { Gas engine } & \\ \text { Jadi, } & 55 \% \quad \times \quad \text { kapasitas } \\ \text { POME } & \text { olahan } \\ = & 55 \% \times 30 \\ = & 16,50 \mathrm{~m}^{3} / \mathrm{jam}\end{array}$

Dengan asumsi densitas POME sama dengan air, yaitu $1.000 \mathrm{~kg} / \mathrm{m}^{3}$ maka kapasitas POME perjam adalah 16,50 $\mathrm{m}^{3} / \mathrm{jam}$ atau 16.500 liter/jam.

Dari hasil pengujian sampel didapatkan nilai COD POME sebesar 62.000 $\mathrm{mg} / \mathrm{l}$ atau sama dengan $0,062 \mathrm{~kg} / \mathrm{l}$, maka kandungan COD dalam POME dapat dihitung sebagai berikut:

$$
\begin{aligned}
\text { COD POME } & =0,062 \times 16.500 \\
& =1,023 \mathrm{~kg} / \mathrm{jam}
\end{aligned}
$$

Dari perhitungan reaksi kimia, bahwa dihasilkan sebesar 0,35 untuk setiap $\mathrm{kg}$ COD, maka dihasilkan adalah:

$$
\begin{aligned}
& =0,35 \times 1,023 \\
& =358,05 \mathrm{~kg}
\end{aligned}
$$

Nilai kalor ditentukan sebesar 8.900 $\mathrm{kkal} / \mathrm{kg}$, maka total kalori terbangkit adalah:

$$
\begin{aligned}
\text { Total Kalori } & =\text { Nilai Kalor } \times \text { total COD } \\
& =8900 \mathrm{kkal} / \mathrm{kg} \times 358.05 \mathrm{~kg} \\
& =3186645 \mathrm{kkal}
\end{aligned}
$$

Konversi dari kkal menjadi Watt thermal adalah 1,163 Watt/kkal (4,186 $\mathrm{kj} / \mathrm{kkal}$ ). Maka total energi dalam Watt adalah:

$$
\begin{aligned}
\text { Energi } & =3186645 \mathrm{kkal} \times 1,163 \mathrm{~W} / \mathrm{kkal} \\
& =3706068 \mathrm{~W} \\
& =3706,068 \mathrm{~kW}
\end{aligned}
$$

Dengan asumsi efisiensi pembangkit gas engine berkisar antara 35\%, maka potensi energi listrik ialah:

$$
\begin{aligned}
\text { Potensi listris } & =\text { energi kalor } \times \text { efisiensi } \\
& =3706,068 \mathrm{~kW} \times 35 \% \\
& =1297 \mathrm{~kW} \\
& =1,3 \mathrm{MW}
\end{aligned}
$$

Dengan demikian, potensi energi listrik dari konversi limbah biogas yang dapat dibangkitkan di PKS UKINDO sebesar $1296,8759 \mathrm{~kW}$ atau 1,3 MW.

\section{SIMPULAN}

Pabrik kelapa sawit PT. Ukindo memiliki potensi sebagai penghasil energi listrik terbarukan, yang diambil dari limbah cair hasil (POME) proses pengolahan di PKS. Berdasarkan hasil 


\section{Husin Ibrahim, Unjuk Kerja Sistem Pembangkit Listrik Menggunakan Biogas Limbah Cair Pada Pabrik Kelapa Sawit}

analisis, daya listrik yang dapat dihasilkan dari limbah POME dengan kapasitas 16.500 liter/jam akan diperoleh daya listrik sebesar 1,3 MW. Perhitungan ini menggunakan asumsi pada produksi TBS terendah. Jika kemudian jumlah TBS diolah lebih besar, maka potensi daya yang dihasilkan jika akan lebih besar, sehingga analisis daya terpasang masih bisa meningkat lagi.

\section{UCAPAN TERIMAKASIH}

Terima kasih kepada Program Studi Teknik Mesin, Universitas Medan Area yang telah membantu dan mendukung sepenuhnya penelitian ini hingga diperoleh hasil dan laporannya.

\section{DAFTAR PUSTAKA}

Diklat PLN (2006), Panjaitan (2013), Unjuk Kerja Generator Biogas.

Deublein dan Steinhauster (2008), konversi POME menjadi biogas.

Febijanto(2010),pengolahankandungan BOD (Biochemical Oxygen Demand) dan COD

Iasrose (2010), Clean and Effient Biomassa Cogenaration Thecnology Asean.

Khudhori (2012), Nugraha S.A (2011), genset berbahan bakar hybrid (biogas- bensin).

Mitzlaff (2000), Alseadi Teodorita et.al. 2008, Engine For Biogas, GTZ Afrika.

Panji (2013), Ahamd A,L(2005), Biogas ; limbah cair pabrik kelapa sawit oleh mikroganisme dalam kondisi aneorobik.

Pulkrabek (2014), Enginering Fundamental of The Internal Combustion..

Sidementasi.Herringshaw (2009), Sistem Biodigester dan Kolam.

Singuda Ensikom(2016), Biogas ; sumber energi listrik.

Thani (1999), dalam ini AGM (2006), chemical oksigen demand (COD), biological demand (BOD).
Winrock International (2015), Melisa (2012), Flametemperatures. 